\title{
Effects of a-Synuclein Monomers Administration in the Gigantocellular Reticular Nucleus on Neurotransmission in Mouse Model
}

\author{
Ilona Joniec-Maciejak ${ }^{1} \cdot$ Agnieszka Ciesielska $^{2} \cdot$ tukasz A. Poniatowski $^{1,3} \cdot$ Adriana Wawer $^{1}$. \\ Anna Sznejder-Pachołek ${ }^{1}$ Ewa Wojnar ${ }^{1} \cdot$ Piotr Maciejak $^{1,4} \cdot$ Dagmara Mirowska-Guzel $^{1,5}$
}

Received: 6 October 2018 / Revised: 12 January 2019 / Accepted: 14 January 2019 / Published online: 13 February 2019

(c) The Author(s) 2019

\begin{abstract}
The aim of the study was to examine the Braak's hypothesis to explain the spreading and distribution of the neuropathological changes observed in the course of Parkinson's disease among ascending neuroanatomical regions. We investigated the neurotransmitter levels (monoamines and amino acid concentration) as well as tyrosine hydroxylase (TH) and transglutaminase-2 (TG2) mRNA expression in the mouse striata (ST) after intracerebral $\alpha$-synuclein (ASN) administration into gigantocellular reticular nucleus (Gi). Male C57BL/10 Tar mice were used in this study. ASN was administrated by stereotactic injection into Gi area $(4 \mu \mathrm{l} ; 1 \mu \mathrm{g} / \mu \mathrm{l})$ and mice were decapitated after 1,4 or 12 weeks post injection. The neurotransmitters concentration in ST were evaluated using HPLC detection. TH and TG2 mRNA expression were examined by Real-Time PCR method. At 4 and 12 weeks after ASN administration we observed decrease of DA concentration in ST relative to control groups and we found a significantly higher concentration one of the DA metabolites-DOPAC. At these time points, we also noticed the increase in DA turnover determined as DOPAC/DA ratio. Additionally, at 4 and 12 weeks after ASN injection we noted decreasing of TH mRNA expression. Our findings corresponds with the Braak's theory about the presence of the first neuropathological changes within brainstem and then with time affecting higher neuroanatomical regions. These results obtained after administration of ASN monomers to the Gi area may be useful to explain the pathogenesis of Parkinson's disease.
\end{abstract}

Keywords $\alpha$-Synuclein $\cdot$ Lewy bodies · Gigantocellular reticular nucleus $\cdot$ Neurotransmission $\cdot$ Parkinson's disease

Ilona Joniec-Maciejak

ijoniec@wum.edu.pl

1 Department of Experimental and Clinical Pharmacology, Centre for Preclinical Research and Technology (CePT), Medical University of Warsaw, Banacha 1B, 02-097 Warsaw, Poland

2 Gladstone Institutes of Neurological Disease, 1650 Owens Street, San Francisco 94158, USA

3 Department of Neurosurgery, Maria Skłodowska-Curie Memorial Cancer Center, Institute of Oncology, W. K. Roentgena 5, 02-781 Warsaw, Poland

4 Department of Neurochemistry, Institute of Psychiatry and Neurology, Sobieskiego 9, 02-957 Warsaw, Poland

5 2nd Department of Neurology, Institute of Psychiatry and Neurology, Sobieskiego 9, 02-957 Warsaw, Poland

\section{Introduction}

Parkinson's disease (PD) is a one of the most common neurodegenerative disease affecting the central nervous system (CNS) characterized by the multitude of motor and nonmotor clinical symptoms [1]. Considering the available long-term epidemiological data the age-standarized annual incidence of PD rates in high-income countries of 14 per 100.000 people while in elderly population ( $\geq 65$ years) is estimated at 160 per 100.000 [2, 3]. The hallmark of PD motor manifestation include progressive tremor, rigidity, bradykinesia and postural instability [4]. The non-motor symptoms include, but are not limited to cognitive impairment, sleep disturbances, autonomic dysfunction and depression [5]. The major pathophysiological process occurring in the course of PD is associated with the degeneration of dopaminergic neurons in the substantia nigra (SN) and more specifically in its pars compacta (SNpc) within brainstem [6]. In this case, progressive loss of dopaminergic neurons results in reduction of the dopamine (DA) and its metabolites 
concentration in the striatum (ST), what directly leads to disruption of homeostasis between neurotransmitter systems and further disturbances of motor function and coordination [7]. The neuronal degeneration within the nigrostriatal pathway as well as in minor level in mesolimbic, mesocortical and hypothalamic dopaminergic pathways is accompanied by appearing of protein inclusions termed Lewy bodies (LB) $[8,9]$. Deposition of the LB is considered as a main histopathological marker for neuronal degeneration observed in PD [10]. The presence of LB is also observed at lower and phylogenetically older structures of CNS such as olfactory bulbs, ventral tegmental area and spinal cord [11-13]. Currently, it is postulated that the outbreak of degenerative changes in the early, asymptomatic stages of PD, could be located in the neurons composing reticular formation (RF) including the gigantocellular reticular nucleus (Gi) within the brainstem. The progression of the neuropathological cascade ascend to the structures of the midbrain leading to the development of pathological protein [14, 15]. It is still unknown what causes the appearance of these inclusions in certain groups of neurons and what is their role in the initiating of the neurodegenerative process. The neuroanatomical correlates of PD progression has been broadly described by Braak et al. in numerous studies [16]. Authors devised their staging system of PD progression by assessing the regional distribution of $\alpha$-synuclein (ASN) immunoreactive inclusion bodies in the brainstems. ASN is a small presynaptic protein expressed throughout the CNS, and it is the main component of LB [17]. For many years it has been accepted that the certain form of ASN is the natively unfolded monomer with a molecular weight of approximately $\sim 14 \mathrm{kDa}$ with a polypeptide chain composed of 140 amino acid residues [18]. However, in 2011 Bartels et al. showed that helically folded tetramer $(\sim 58 \mathrm{kDa})$ is a dominant form of ASN in the CNS [19]. Many experimental and clinical data indicate that an abnormal conformation or excessive accumulation of ASN in the brain can induce neurotoxicity leading to the progressive neurodegeneration observed in PD [20]. A deviation from normal physiological concentrations of ASN can affect the homeostasis of dopaminergic system and induce changes in the synthesis and metabolism of DA [21]. The recent data indicated the possible involvement of transglutaminase 2 (TG2) in several neurodegenerative processes present in PD by catalyzing the formation of protein aggregates [22, 23]. TG2 belongs to the family of transamidating acyltransferases that catalyzes a $\left(\mathrm{Ca}^{2+}\right)$-dependent protein modifications and may also act as GTPase/ATPase, protein disulfide isomerase and protein kinase $[24,25]$. The aim of the present study was to determine the effect of elevated concentrations of recombinant human ASN monomers in the brainstem of male C57BL/10 Tar mice at the initiation and progression of dopaminergic neurons loss in the nigrostriatal pathways defined as the DA and its metabolites concentration and tyrosine hydroxylase (TH) messenger RNA (mRNA) expression in the ST. We examined also the TG2 mRNA expression to assess its potential role in our model. Recombinant human protein ASN monomers was bilaterally administered to the Gi area of the brainstem by stereotactic injection to initiate the neuropathological cascade.

\section{Materials and Methods}

\section{Animals}

Male C57BL/10 Tar mice at the age of 12 months (body weight of $35-38 \mathrm{~g}$ ) were used in this study. Animals were housed in groups of 3-5/cage in standard laboratory conditions at the controlled temperature $\left(22 \pm 5{ }^{\circ} \mathrm{C}\right)$ and $60 \pm 5 \%$ humidity with a $12 \mathrm{~h}$ light/dark cycle (7:00 a.m./7:00 p.m.). All animals were given ad libitum access to food and water. The study groups consist total number of 18 animals $(n=18)$ with 6 animals $(n=6)$ in each of three subgroups was distinguished and allocated on the basis of length of the period after performed stereotactic injections (Fig. 1). The control groups of animals $(n=18)$ were designed in the same manner (Fig. 1). The experimental protocols were approved by the 2nd Local Ethics Committee in Warsaw and were conducted in accordance with European Union (EU) Directive 2010/63/EU on the protection of animals used for scientific purposes and National Research Council (NRC) Committee for the Update of the Guide for the Care and Use of Laboratory Animals (8th edition; National Academies Press 2011). All efforts were made to reduce the number of animals used and to minimize animals suffering.

\section{Stereotactic Injections}

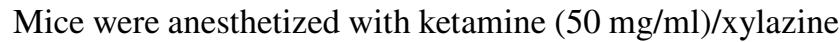
$(20 \mathrm{mg} / \mathrm{ml})$ combination $(1: 1, \mathrm{v} / \mathrm{v})$ in the dose of $2 \mathrm{ml} / \mathrm{kg}$ via intraperitoneal (i.p.) injection. After the induction of anesthesia, mice were placed and their heads were stabilized at three points by two blunt ear bars and anterior bite bar in a stereotactic frame (51900; Stoelting, Wood Dale, IL, USA) with an additional adaptor (51625; Stoelting, Wood Dale, IL, USA). The longitudinal incision was made in the skin overlying the skull exposing both the sagittal and coronal sutures of the skull and then burr-hole was made with a needle just above the infusion site based on the scheduled coordinates. Injection and infusion were performed using a microsyringe pump (UMP2; World Precision Instruments, Sarasota, FL, USA) connected with a programmable controller (Micro 4; World Precision Instruments, Sarasota, FL, USA). A programmable microsyringe pump was used to deliver $4 \mu$ of human recombinant ASN (S7820; Sigma-Aldrich, St. Louis, MO, USA) dissolved in sterile $0.9 \%$ saline solution $(\mathrm{NaCl})$ 
Fig. 1 Schematic timelines showing the experiment design and procedures performed on study or control groups. ASN $\alpha$-synuclein, $\mathrm{NaCl}$ saline solution. $S I$ stereotactic injection, $G i$ gigantocellular reticular nucleus
STUDY GROUPS - ASN:

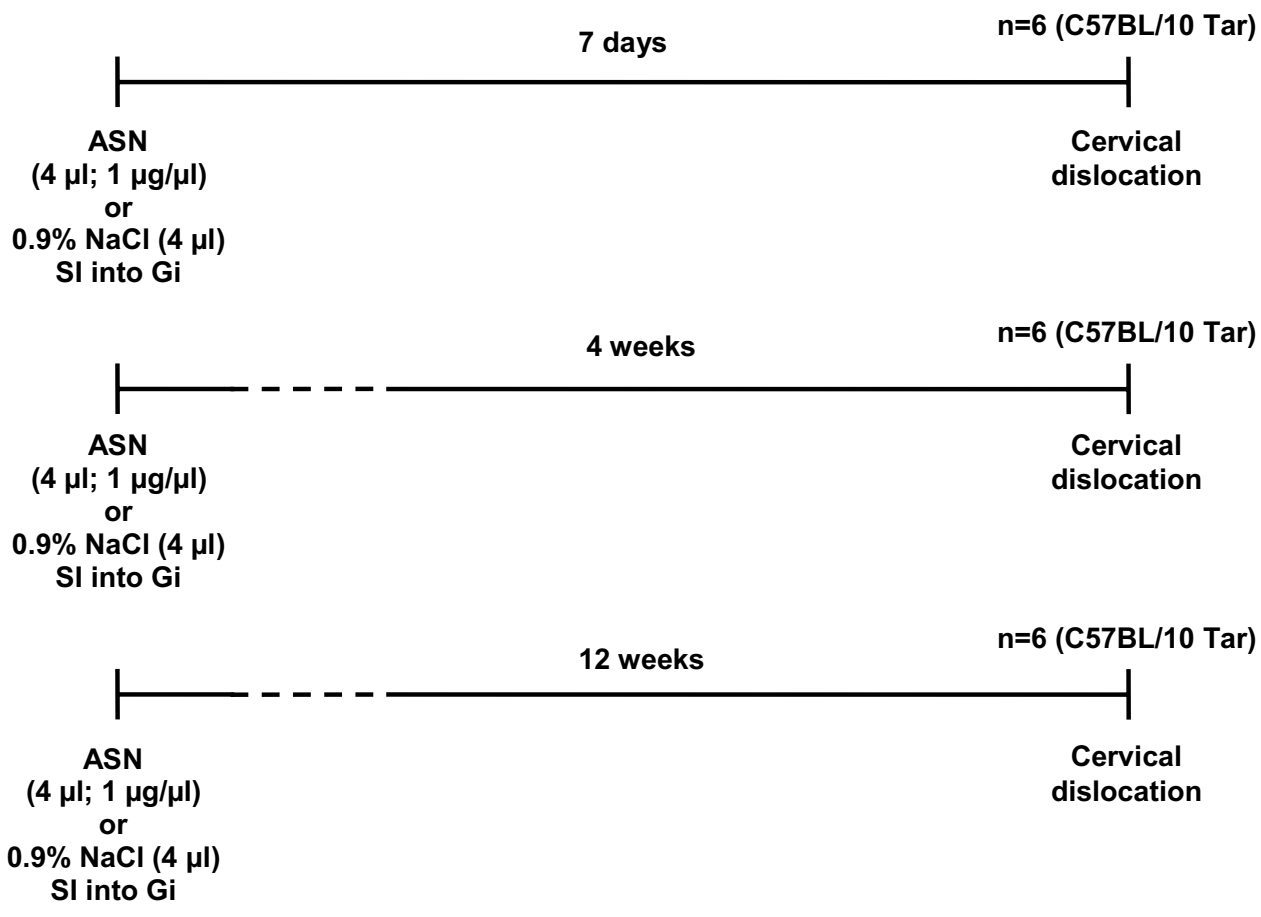

with concentration of $1 \mu \mathrm{g} / \mu \mathrm{l}$ into $\mathrm{Gi}$ at the following stereotactic coordinates-AP (y): $-5.91, \mathrm{ML}(\mathrm{x}): 0.00$ relative to bregma and DV (z): $-5 \mathrm{~mm}$ relative to dura (Paxinos $\mathrm{G}$, Franklin KBJ. The Mouse Brain in Stereotaxic Coordinates, 2nd Edition; Academic Press, 2001, San Diego, CA, USA). ASN was administered at estimated $0.5 \mathrm{ml} / \mathrm{min}$ rate. After infusion, the scalp was closed with 5-0 monofilament nylon sutures on $16 \mathrm{~mm}$ cutting needle of $3 / 8$ circle (DK05PA; Yavo, Poland). Animals from the control groups received identical anesthesia and stereotactic injection with the administration of equal volume of $\mathrm{NaCl}$.

\section{Tissue Dissection and Preparation}

The animals were euthanized by cervical dislocation and decapitated at 1, 4 and 12 weeks after ASN or $\mathrm{NaCl}$ injection. The intact brain was rapidly and completely removed from the skull and put on an ice-cold glass plate. Both, right and left ST were microsurgically dissected using a laboratory microscope (SK-292H; Opta-Tech, Warsaw, Poland) with dedicated tools, weighed (XS105 Dual Range; Mettler Toledo, Greifensee, Switzerland) and then immediately placed in dry ice $\left(\mathrm{CO}_{2}\right)$ and stored at $-80{ }^{\circ} \mathrm{C}$ until further use. The obtained ST were used for consecutive determination of monoamines and amino acid neurotransmitters assay concentration as well as both, TH and TG2 mRNA expression. All operations were carried out in a highly reproducible manner so as to exclude any significant its impact on the results obtained.

\section{High-Performance Liquid Chromatography (HPLC) Analysis}

\section{Assay of Monoamines Concentration}

The examined ST concentration of DA and its corresponding metabolites: 3,4-dihydroxyphenylacetic acid (DOPAC), 3-methoxytyramine (3-MT), homovanillic acid (HVA) and 3,4-dihydroxyphenylethanolamine (NA) as well as 5-hydroxytryptamine (5-HT) with it metabolite: 5-hydroxyindolacetic acid (5-HIAA) were determined by HPLC method according to the method described previously by Joniec-Maciejak et al. [26]. The HPLC system consisted of a delivery pump (Mini-Star K-500; Knauer, Berlin Germany), an autosampler automatic injector (LaChrom L-7250; Merck-Hitachi, Darmstadt/Tokyo, Germany/Japan), an electrochemical detector (L-3500A; Merck-Recipe, Darmstadt/Munich, Germany) with a glassy-carbon working electrode. The analysis was performed at a potential $+0.8 \mathrm{~V}$ vs. an $\mathrm{Ag} / \mathrm{AgCl}$ reference electrode. Immediately, before the analysis the striata were homogenized in ice-cold solution containing $0.1 \mathrm{~N}$ perchloric acid $\left(\mathrm{HClO}_{4}\right.$; Sigma-Aldrich, St. Louis, MO, USA) and $0.05 \mathrm{mM}$ ascorbic acid $\left(\mathrm{C}_{6} \mathrm{H}_{8} \mathrm{O}_{6}\right.$, Sigma-Aldrich, St. Louis, MO, USA) and centrifuged (Labofuge 400R; Heraeus Instruments, Hanau, Germany) at $13.000 \times g$ for 15 min at $4{ }^{\circ} \mathrm{C}$. 
The supernatant was filtered through a $0.2 \mu \mathrm{m}$ pore size PTFE membrane syringe filter (6792-1302 Puradisc; Whatman, UK). Monoamines were separated isocratically using EC 250/4 Nucleosil 100-5 C18AB (250 mm length $\times 4 \mathrm{~mm}$ internal diameter, $5 \mu \mathrm{m}$ particle size, $100 \AA$ ) HPLC column (720936.40; Macherey-Nagel, Düren, Germany). The mobile phase comprised $34 \mathrm{mM}$ citric acid $\left(\mathrm{C}_{6} \mathrm{H}_{8} \mathrm{O}_{7}\right)$ buffer (SigmaAldrich, St. Louis, MO, USA), $32 \mathrm{mM}$ sodium phosphate $\left(\mathrm{NaH}_{2} \mathrm{PO}_{4}\right)$ buffer (Sigma-Aldrich, St. Louis, MO, USA), $1 \mathrm{mM}$ octane sulfonic acid $\left(\mathrm{C}_{8} \mathrm{H}_{18} \mathrm{O}_{3} \mathrm{~S}\right)$ buffer (SigmaAldrich, St. Louis, MO, USA), $54 \mathrm{mM}$ ethylenediaminetetraacetic acid (EDTA) buffer (Sigma-Aldrich, St. Louis, MO, USA) and $12 \%$ methanol (Merck, Darmstadt, Germany) in ultrapure water $(18 \mathrm{M} \Omega \mathrm{cm})$.

The chromatograms were recorded and integrated by use of the computerized data acquisition Clarity software (version 5.0; DataApex, Prague, Czech Republic). The monoamines concentrations were quantified and calculated by comparison with the standard reference solutions (external calibration). All used monoamines standards were purchased from Sigma-Aldrich-St. Louis, MO, USA. The monoamines concentrations in the sample were expressed as $\mathrm{pg} / \mathrm{mg}$ wet tissue.

\section{Assay of Amino Acid Concentration}

The examined ST concentration of the amino acids: aspartate (ASP), glutamate (GLU), histidine (HIS), alanine (ALA), taurine (TAU) and $\gamma$-aminobutyric acid (GABA) in the samples was performed by HPLC with electrochemical detection according to the method described previously by Joniec-Maciejak et al. [26]. The chromatograph system consisted of an electrochemical detector (EC3000; Recipe, Munich, Germany), an autosampler (Primaide 1210; Hitachi, Tokyo, Japan) and the pump (Primaide 1110, Hitachi, Tokyo, Japan). To obtain agents for derivatisation $22 \mathrm{mg}$ o-phthaldialdehyde (OPA) reagent (Fluka, Buchs, Switzerland) was diluted in $0.5 \mathrm{ml}$ of $1 \mathrm{M}$ sodium sulphite $\left(\mathrm{Na}_{2} \mathrm{SO}_{3}\right)$, $0.5 \mathrm{ml}$ of methanol, $0.9 \mathrm{ml}$ of $0.1 \mathrm{M}$ sodium tetraborate $\left(\mathrm{Na}_{2} \mathrm{~B}_{4} \mathrm{O}_{7}\right)$ buffer adjusted to $\mathrm{pH} 10.4$ using $5 \mathrm{M}$ sodium hydroxide $(\mathrm{NaOH})$. The derivatising agent $(20 \mu \mathrm{l})$ was reacted with amino acid standard $(1 \mathrm{ml})$ or with supernatant samples $(1 \mathrm{ml})$ for $15 \mathrm{~min}$. The separation of amino acids was performed using a Luna $5 \mu \mathrm{m} \mathrm{C} 18(2) 100 \AA$ (250 mm length $\times 4.6 \mathrm{~mm}$ internal diameter) HPLC reverse phase column (00G-4252-E0; Phenomenex, Torrance, CA, USA). The mobile phase comprised of $45 \mathrm{mM}$ disodium phosphate $\left(\mathrm{Na}_{2} \mathrm{HPO}_{4}\right)$ buffer (Sigma-Aldrich, St. Louis, MO, USA), $0.2 \mathrm{M}$ citric acid buffer (Sigma-Aldrich, St. Louis, MO, USA) and $0.15 \mathrm{mM}$ EDTA buffer (Sigma-Aldrich., St. Louis, MO, USA) containing 24\% methanol (Merck, Darmstadt, Germany). Preparation of the mobile phase and the derivatising agents were based on the method developed by
Rowley et al. with minor modifications [27]. Samples were quantified by comparison with standard reference solutions (external calibration) and concentrations calculated with Primaide (version 1.0; Merck, Darmstadt, Germany). All amino acid standards were purchased from Sigma-AldrichSt. Louis, MO, USA. The concentration of amino acids in the sample was expressed as ng/mg of wet tissue.

\section{Real-Time Polymerase Chain Reaction (Real-Time PCR)}

The striatal mRNA expression levels of TH and TG2 were evaluated using Real-Time PCR. Total RNA isolation was performed using TRI Reagent (Sigma-Aldrich, St. Louis, MO, USA) in accordance with the manufacturer's instructions. The striatal mRNA expression levels of TH and TG2 were evaluated using Real-Time PCR. Total RNA isolation was performed using TRI Reagent (Sigma-Aldrich, St. Louis, MO, USA) in accordance with the manufacturer's instructions. The concentration of obtained RNA was measured spectrophotometrically at wavelength of $260 \mathrm{~nm}$ (BioPhotometer, Eppendorf AG, Hamburg Germany). The single-strand complementary DNA (cDNA) was synthesized from total RNA using a PrimeScript RT Reagent (Perfect Real Time; Takara Bio, Otsu, Japan) in a SensoQuest Labcycler (SensoQuest GmbH, Göttingen, Germany). The incubation conditions for reverse transcription consisted of $15 \mathrm{~min}$ at $37^{\circ} \mathrm{C}$ followed by $5 \mathrm{~s}$ at $85^{\circ} \mathrm{C}$. Following the reverse transcription reaction, the cDNA products were stored at $-20{ }^{\circ} \mathrm{C}$ until further use. Real-Time PCR was performed on a RotorGene Q 5plex HRM System (Qiagen Benelux BV, Velno, The Netherlands). The cDNA was amplified with gene-specific primers designed using the publicly available National Center for Biotechnology Information (NCBI) Primer-BLAST software tool (Table 1). To eliminate sampletosample differences

Table 1 Primer sequences used for Real-Time PCR amplification

\begin{tabular}{|c|c|c|}
\hline \multirow{2}{*}{$\begin{array}{l}\text { Target } \\
\mathrm{TH}\end{array}$} & Real-time PCR primer sequences $\left(5^{\prime}-3^{\prime}\right)$ & \multirow{2}{*}{$\begin{array}{l}\text { Predicted } \\
\text { product size } \\
\text { (bp) }\end{array}$} \\
\hline & F 5'-AACCTACCAGCCGGTGTACT-3' & \\
\hline & R 5'-AGAGAATGGGCGCTGGATAC-3' & \\
\hline \multirow[t]{2}{*}{ TG2 } & F 5'-TCAGCAAGTGAAGTACGGGC-3' & \multirow[t]{2}{*}{106} \\
\hline & R 5'-GGCGGAGTTGTAGTTGGTCA-3' & \\
\hline \multirow[t]{2}{*}{ GAPDH } & $\begin{array}{l}\text { F 5'-TCTCCCTCACAATTTCCATCC } \\
\text { CAG-3' }\end{array}$ & \multirow[t]{2}{*}{100} \\
\hline & $\begin{array}{l}\text { R 5'-GGGTGCAGCGAACTTTATTGA } \\
\text { TGG-3' }\end{array}$ & \\
\hline
\end{tabular}

$T H$ tyrosine hydroxylase, $T G 2$ transglutaminase 2, GAPDH glyceraldehyde 3-phosphate dehydrogenase, $F$ forward primer, $R$ reverse primer 
in RNA extraction and conversion to cDNA, we amplified the housekeeping gene glyceraldehyde 3-phosphate dehydrogenase (GAPDH) in each sample. Each PCR mixture contained $1 \mu \mathrm{l}$ of cDNA along with $10 \mu \mathrm{l}$ of FastStart Essential DNA Green Master (Roche Molecular Systems, Alameda, CA, USA) and $1.25 \mu \mathrm{l}(10 \mu \mathrm{M})$ of each primer in a total reaction volume of $20 \mu \mathrm{l}$. The amplification protocol was as follows: initial denaturation at $95^{\circ} \mathrm{C}$ for $10 \mathrm{~min}$; 40 cycles at $95{ }^{\circ} \mathrm{C}$ for $15 \mathrm{~s}, 58{ }^{\circ} \mathrm{C}$ for $15 \mathrm{~s}$ and $72{ }^{\circ} \mathrm{C}$ for $15 \mathrm{~s}$. Melting-curve analysis was applied to all reactions in order to ensure the consistency and specificity of the amplified product. All the amplifications were carried out in duplicate. The relative expression of the genes was calculated using Pfaffl method [28].

\section{Statistical Analysis}

Data were analyzed using Statistica 9.0 PL (StatSoft Inc., Tulsa, OK, USA) software package for Windows. To test for differences between the groups Mann-Whitney U test were used. The results were considered statistically significant when $\mathrm{p}$-values were less than $0.05(\mathrm{p}<0.05)$. Data are presented as a mean value \pm SEM.

\section{Results}

\section{Effect of ASN Administration on ST Monoamines and Amino Acid Concentration}

The ASN treatment groups presented reduced DA in ST (Fig. 2a) and increased DOPAC concentration (Fig. 2b) compared with the $\mathrm{NaCl}$ groups in 4 and 12 weeks after injection. 3-MT concentration was increased 4 weeks after ASN administration (Fig. 2d). The level of HVA persisted unchanged (Fig. 2c). The DA turnover rate was estimated by the ratio of the DOPAC to DA, the ratio of 3-MT to DA and the ratio of HVA to DA. ASN administration caused an increase in dopamine turnover (DOPAC/DA) in 4 and 12 weeks (Fig. 2e) and both, 3-MT/DA and HVA/ DA ratios in 4 weeks compared to $\mathrm{NaCl}$ groups (Fig. 2fg). ASN injection increased 5HT concentration at 1 week but on the contrary reduced at 4 weeks (Fig. 2i) whereas the level of 5-HIAA, a serotonin metabolite, remained unchanged (Fig. 2j). The ASN treatment also had no effect on the ratio of 5-HIAA/5-HT as an index of 5HT turnover (Fig. 2k). ASN injection led to the increase of GABA $(\mathrm{p}<0.05)$ (Fig. 2l) and HIS concentration at time point of 4 weeks. ASN had no influence on the TAU, ALA, ASP and GLU levels in ST compared to the control groups.

\section{Effect of ASN Administration on ST mRNA Expression for TH and TG2}

ASN treatment reduced TH mRNA expression in ST compared to the control groups in 4 and 12 weeks after ASN or $\mathrm{NaCl}$ injection into Gi (Fig. 3a). The TG2 mRNA expression in ST remained unchanged post ASN administration into Gi (Fig. 3b).

\section{Discussion}

The pathogenesis of PD is characterized by a slow but progressive and long-lasting process of dopaminergic neuronal degeneration [29]. This multistep cytopathological phenomenon is occurring mainly within non-myelinated fibers and specific structures in CNS successive affecting its higher systems and neuroanatomical regions [30, 31]. The initial neuropathological changes are observed in medulla oblongata, ventral tegmental area and olfactory bulbs [32]. According to the staging model proposed by Braak et al. this first asymptomatic phase (stage 1 and 2) is characterized by lack of the clinically detectable symptoms [33]. In this case clinical presentation occurs at the time of neurodegeneration occurring within SN and other nuclei situated in midbrain and forebrain (stage 3 and 4). Advanced and severe lesions are characterized by degeneration within neocortex (stage 5 and 6). Despite numerous pre- and clinical studies, we do not yet know the phenomena in regard of initiation of neuropathological changes, but many potential factors are currently postulated [34]. Insights afforded by detailed research indicate the significance of the excessive deposition and toxicity of ASN within CNS [35]. Nevertheless, ASN is a constitutive protein widely expressed by several neuronal populations serving in the regulation of neurotransmission and mobilization of synaptic vesicles, including DA metabolism and turnover [36]. It was observed that generated $\mathrm{ASN}^{-/-}$hybrid $129 \mathrm{SV} / \mathrm{j} \times \mathrm{C} 57 \mathrm{BL} / 6$ F2 mice exhibited a reduction of DA levels in ST associated with attenuation of DA-dependent locomotor response to amphetamine $\left(\mathrm{C}_{9} \mathrm{H}_{13} \mathrm{~N}\right)$ [37]. As it was mentioned, the predominant physiological type of ASN is related to its native folded tetrameric form which in different conditions could undergo structural modification leading to its disassemblyand generation of unstable monomeric form [38, 39]. These liberated monomeric conformers of ASN present susceptibility to misfolding and pathological aggregation forming oligomers which are mainly responsible for neuronal toxicity and increased presence of abnormal spherical structures referred to as LB [40]. The LB constitute cytoplasmic inclusions which are characteristic for patients with PD and other synucleinopathies [41]. In pathological terms the unfavorable dyshomeostasis of tetrameric multimers and an absolute 

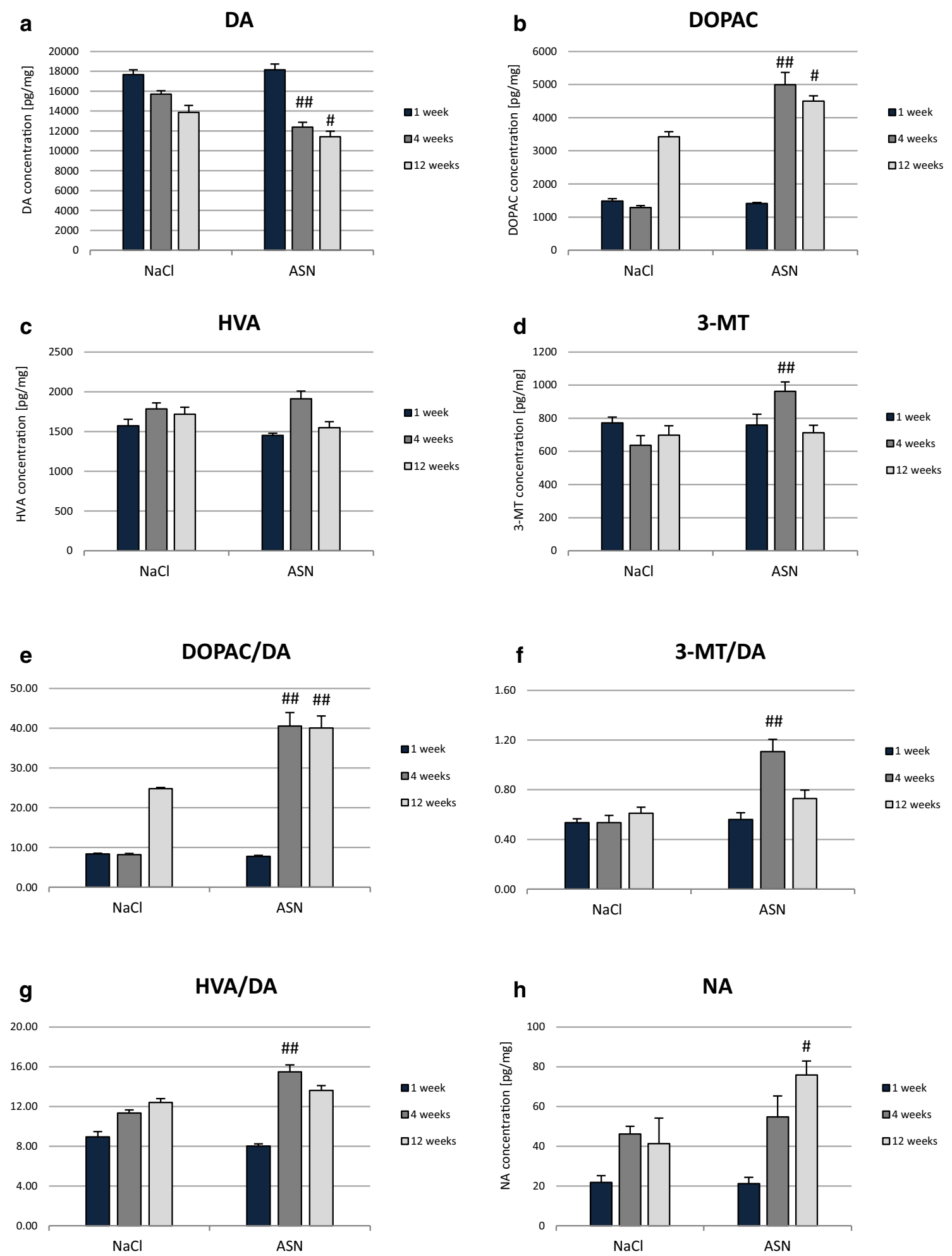

Fig. 2 Concentration of DA (a), DOPAC (b), HVA (c), 3-MT (d) and DOPAC/DA (e), 3-MT/DA (f), HVA/DA (g) ratio as well as concentration of NA (h), 5-HT (i), 5-HIAA (j), and 5HIAA/5HT (k) ratio and GABA (1) concentration in the ST of C57BL/10 Tar mice in 1,

4 and 12 weeks post $\mathrm{ASN}$ or $\mathrm{NaCl}$ injection into Gi area. Data represent means \pm SEM of $6(n=6)$ mice per group. \#Differs from $\mathrm{NaCl}$ (control) group, ${ }^{\#} \mathrm{p}<0.05,{ }^{\# \#} \mathrm{p}<0.01$ 
i

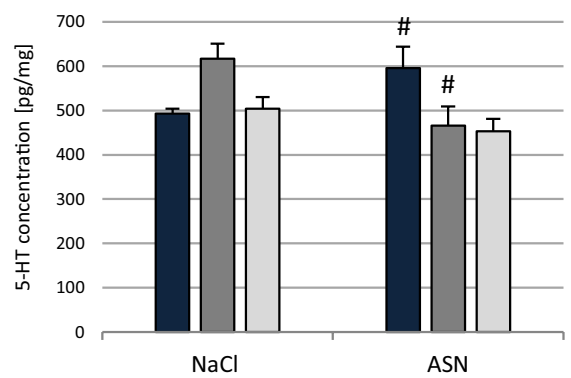

$\mathbf{k}$

5-HIAA/5-HT

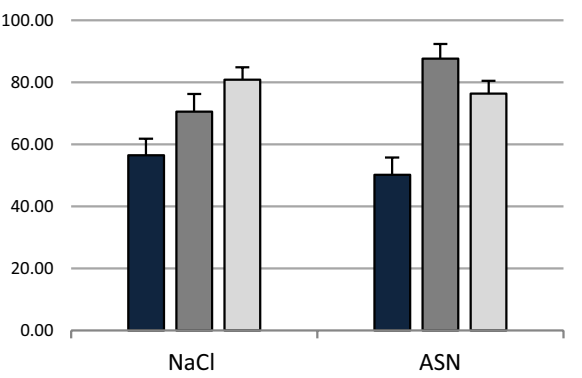

j

5-HIAA

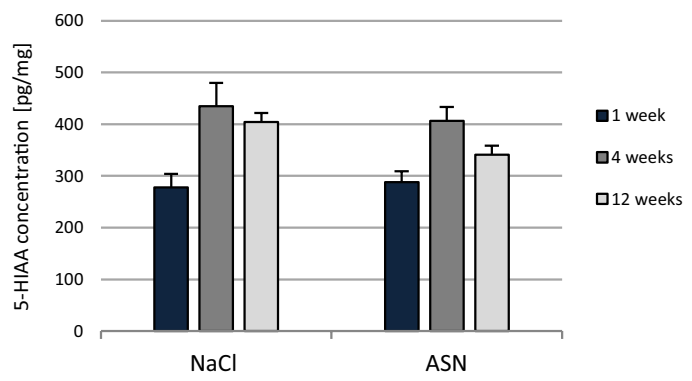

I

GABA

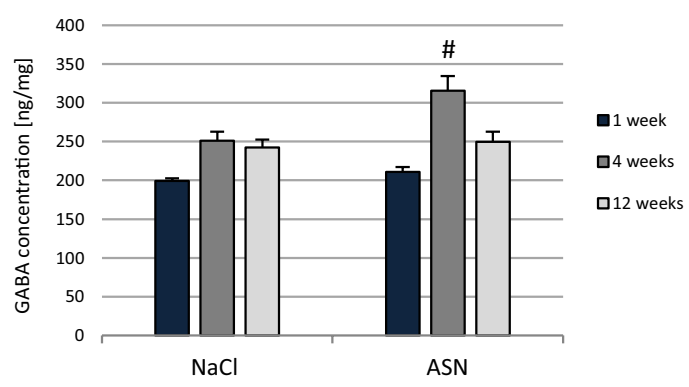

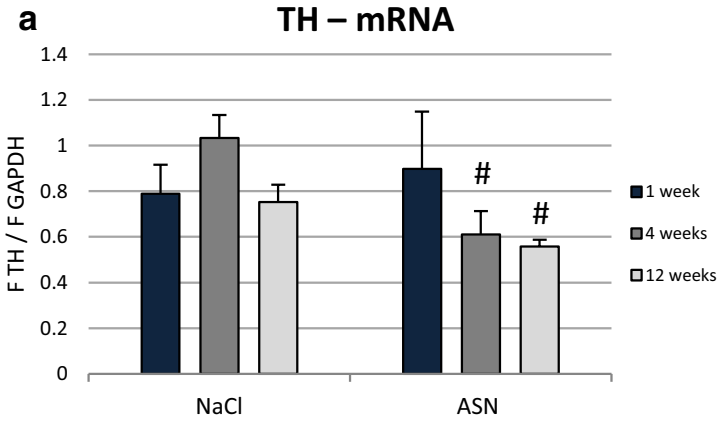

Fig. 3 Changes in the expression of mRNA for TH (a) and TG2 (b) normalized to GAPDH in the ST of C57BL/10 Tar mice 1, 4 and 12 weeks post $\mathrm{ASN}$ or $\mathrm{NaCl}$ injection into $\mathrm{Gi}$ area. The data are pre-

increase of ASN monomers proportion could influence DA biosynthesis regulation and its mediated neurotransmission $[42,43]$. According to the current understanding the originof the neuropathological changes in early phase of the disease is situated within medulla oblongata nuclei including the Gi and its interconnections [44]. In accordance with these findings the purpose of our study was to evaluate effects of direct injection of ASN monomers into Gi area in which the occurrence of primary changes in the course of PD was postulated. To our knowledge, this is the first study to analyze that phenomenon after direct intracerebral administration of human recombinant ASN monomers into $\mathrm{Gi}$ area in mice. After ASN administration we have observed

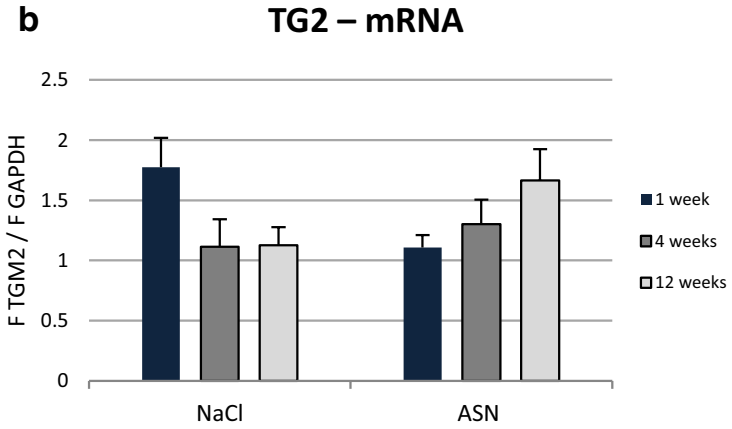

sented as the mean \pm SEM of $6(n=6)$ mice per group. \#Differs from $\mathrm{NaCl}$ (control) group, ${ }^{*} \mathrm{p}<0.05$

changes regarding DA concentration in ST which were visible 4 weeks after injection. Then a significantly lower concentration of DA in ST relative to $\mathrm{NaCl}$ group was demonstrated. The same changes were observed 12 weeks after ASN administration. At these time points, we also observed decreasing TH mRNA expression in ST which was involved in the production of DA. Previous studies have shown that overexpression of ASN has been found to inhibit expression and activity of TH [45]. In 4 and 12 weeks after ASN administration we also observed a tendency for increased TG2 mRNA expression which was not significant. TG2 is the enzyme which catalyzes the deamination and transacylation of proteins [46]. The control of protein oligomerization by 
TG2 is a cause for the formation of insoluble macromolecular aggregates [47]. ASN inclusions are present in degenerating neurons in Parkinson's disease [48]. Overexpression of TG2 has been observed in apoptotic cells [49]. The study of Andringa et al. demonstrated that many of the ASN monomers in the course of PD are crosslinked by TG2 and thus the function of SN may be impaired [50]. This modification appears to be an early step in PD pathogenesis, preceding the aggregation of ASN in Lewy bodies [51]. These findings correspond with a theory proposed by Braak et al. that the first neuropathological changes, including deposits of ASN, are observable within brainstem and then with time affecting higher neuroanatomical regions [32,33]. At the same time points ( 4 and 12 weeks) after injection we found a significantly higher concentration of the DOPAC. In 4 weeks after administration of ASN we also found a higher concentration of 3-MT. These data indicate that the increased concentration of ASN in Gi area is associated with the increase of DA metabolism in ST. This observation is also confirmed by the significant increase in DA turnover in ST determined as ratios: DOPAC/DA, 3-MT/DA and HVA/DA. On this basis we can assume that this is most likely an effect of increased activity of neurochemical DA metabolizing enzymes such as monoamine oxidase B (MAO-B) and catechol-O-methyltransferase (COMT) [52]. In addition, DA metabolism is linked to the concomitant production of DOPAC and hydrogen peroxide $\left(\mathrm{H}_{2} \mathrm{O}_{2}\right)$ which may be responsible for neuronal damage [53]. Directly administrated ASN initiates neurotoxic changes, reflecting the early stage of PD. However, we are of an opinion that the single injection of ASN may not be enough to intensify these changes. We suppose that the ASN potentially degraded because it was unable to demonstrate its presence by immunohistochemical (IHC) staging. It corresponds with the results demonstrated by MasudaSuzukake et al. which indicate that ASN degrades after 5-7 days after administration [54]. In accordance with data considering serotonergic transmission, we have shown that ASN injection into Gi results in a 5-HT increase in ST at 1 week after but the decrease at 4 weeks after infusion. On the contrary, there was no influence of ASN administration on ST concentration of 5-HIAA and there was no change in 5-HT metabolism calculated as 5-HIAA/5-HT ratio. This is consistent with a slow and non-linear dysfunction of serotonergic transmission due to its associated neuron loss observed in positron emission tomography (PET) examination, indirectly confirming the specificity of our model [55]. As PD is associated with the imbalance of the entire neurotransmitter system, we have performed an assay to asses amino acid concentration [56, 57]. Typical changes such as increased concentration of HIS and GABA were observed in 4 weeks after ASN administration. Our research was based on a direct stereotactic injection of ASN monomers into the $\mathrm{Gi}$ area, where primary changes in the course of PD are postulated. This is a new mouse model of PD and should be useful for elucidating progression mechanisms and evaluating disease-modifying therapy.

Acknowledgements This study was supported by Grant N N401 066638 conducted in the years 2010-2013 from the Ministry of Science and Higher Education-Warsaw, Poland. The project was implemented with the Centre for Preclinical Research and Technology (CePT) infrastructure financed by the European Union (EU) - The European Regional Development Fund (ERDF) within the "Innovative Economy" operational program for years 2007-2013. No additional external funding and support was received for this study.

Author Contributions IJ-M and AC designed research; IJ-M, AW, ASZ-P and EW performed research; IJ-M and PM analyzed data; and $\mathrm{IJ}-\mathrm{M}$ and $\mathrm{LAP}$ wrote the paper, IJ-M, AW discussed, reviewed and edited the manuscript; AC, PM and DM-G reviewed and edited the manuscript.

\section{Compliance with Ethical Standards}

Conflict of interest The authors declare that they have no conflict of interest.

Ethical Approval All applicable international, national, and institutional guidelines for the care and use of animals were followed.

Open Access This article is distributed under the terms of the Creative Commons Attribution 4.0 International License (http://creativeco mmons.org/licenses/by/4.0/), which permits unrestricted use, distribution, and reproduction in any medium, provided you give appropriate credit to the original author(s) and the source, provide a link to the Creative Commons license, and indicate if changes were made.

\section{References}

1. Poewe W, Seppi K, Tanner CM, Halliday GM, Brundin P, Volkmann J, Schrag AE, Lang AE (2017) Parkinson disease. Nat Rev Dis Primers 3:17013. https://doi.org/10.1038/nrdp.2017.13

2. Ascherio A, Schwarzschild MA (2016) The epidemiology of Parkinson's disease: risk factors and prevention. Lancet Neurol 15:1257-1272. https://doi.org/10.1016/S1474-4422(16)30230-7

3. Hirtz D, Thurman DJ, Gwinn-Hardy K, Mohamed M, Chaudhuri AR, Zalutsky R (2007) How common are the "common" neurologic disorders? Neurology 68:326 - 37. https://doi. org/10.1212/01.wnl.0000252807.38124.a3

4. Moustafa AA, Chakravarthy S, Phillips JR, Gupta A, Keri S, Polner B, Frank MJ, Jahanshahi M (2016) Motor symptoms in Parkinson's disease: a unified framework. Neurosci Biobehav Rev 68:727-740. https://doi.org/10.1016/j.neubiorev.2016.07.010

5. Schapira AHV, Chaudhuri KR, Jenner P (2017) Non-motor features of Parkinson disease. Nat Rev Neurosci 18:435-450. https ://doi.org/10.1038/nrn.2017.62

6. Sulzer D, Surmeier DJ (2013) Neuronal vulnerability, pathogenesis, and Parkinson's disease. Mov Disord 28:41-50. https://doi. org/10.1002/mds. 25095

7. Barone P (2010) Neurotransmission in Parkinson's disease: beyond dopamine. Eur J Neurol 17:364-376. https://doi.org/10.1 111/j.1468-1331.2009.02900.x 
8. Haber SN (2014) The place of dopamine in the cortico-basal ganglia circuit. Neuroscience 282:248-257. https://doi.org/10.1016/j. neuroscience.2014.10.008

9. Kasanuki K, Heckman MG, Diehl NN, Murray ME, Koga S, Soto A, Ross OA, Dickson DW (2017) Regional analysis and genetic association of nigrostriatal degeneration in Lewy body disease. Mov Disord 32:1584-1593. https://doi.org/10.1002/mds.27184

10. Wakabayashi K, Tanji K, Mori F, Takahashi H (2007) The Lewy body in Parkinson's disease: molecules implicated in the formation and degradation of alpha-synuclein aggregates. Neuropathology 27:494-506. https://doi.org/10.1111/j.1440-1789.2007.00803 . $\mathrm{x}$

11. Beach TG, White CL 3rd, Hladik CL, Sabbagh MN, Connor DJ, Shill HA, Sue LI, Sasse J, Bachalakuri J, Henry-Watson J, Akiyama H, Adler CH, Arizona Parkinson's Disease Consortium (2009) Olfactory bulb alpha-synucleinopathy has high specificity and sensitivity for Lewy body disorders. Acta Neuropathol 117:169-174. https://doi.org/10.1007/s00401-008-0450-7

12. Seidel K, Mahlke J, Siswanto S, Krüger R, Heinsen H, Auburger G, Bouzrou M, Grinberg LT, Wicht H, Korf HW, den Dunnen W, Rüb U (2015) The brainstem pathologies of Parkinson's disease and dementia with Lewy bodies. Brain Pathol 25:121-135. https ://doi.org/10.1111/bpa.12168

13. Del Tredici K, Braak H (2012) Spinal cord lesions in sporadic Parkinson's disease. Acta Neuropathol 124:643-664. https://doi. org/10.1007/s00401-012-1028-y

14. Del Tredici K, Rüb U, De Vos RA, Bohl JR, Braak H (2002) Where does parkinson disease pathology begin in the brain? J Neuropathol Exp Neurol 61:413-426. https://doi.org/10.1093/ jnen/61.5.413

15. Gambardella S, Ferese R, Biagioni F, Busceti CL, Campopiano R, Griguoli AMP, Limanaqi F, Novelli G, Storto M, Fornai F (2017) The monoamine brainstem reticular formation as a paradigm for re-defining various phenotypes of Parkinson's disease owing genetic and anatomical specificity. Front Cell Neurosci 11:102. https://doi.org/10.3389/fncel.2017.00102

16. Braak E, Sandmann-Keil D, Rüb U, Gai WP, de Vos RA, Steur EN, Arai K, Braak H (2001) alpha-synuclein immunopositive Parkinson's disease-related inclusion bodies in lower brain stem nuclei. Acta Neuropathol 101:195-201. https://doi.org/10.1007/ s004010000247

17. Kalia LV, Kalia SK (2015) $\alpha$-Synuclein and Lewy pathology in Parkinson's disease. Curr Opin Neurol 28:375-381. https://doi. org/10.1097/WCO.0000000000000215

18. Lashuel HA, Overk CR, Oueslati A, Masliah E (2013) The many faces of $\alpha$-synuclein: from structure and toxicity to therapeutic target. Nat Rev Neurosci 14:38-48. https://doi.org/10.1038/nrn34 06

19. Bartels T, Choi JG, Selkoe DJ (2011) $\alpha$-Synuclein occurs physiologically as a helically folded tetramer that resists aggregation. Nature 477:107-110. https://doi.org/10.1038/nature10324

20. Breydo L, Wu JW, Uversky VN (2012) A-synuclein misfolding and Parkinson's disease. Biochim Biophys Acta 1822:261-285. https://doi.org/10.1016/j.bbadis.2011.10.002

21. Venda LL, Cragg SJ, Buchman VL, Wade-Martins R (2010) $\alpha$-Synuclein and dopamine at the crossroads of Parkinson's disease. Trends Neurosci 33:559-568. https://doi.org/10.1016/j. tins.2010.09.004

22. Grosso H, Woo JM, Lee KW, Im JY, Masliah E, Junn E, Mouradian MM (2014) Transglutaminase 2 exacerbates $\alpha$-synuclein toxicity in mice and yeast. FASEB J 28:4280-4291. https://doi. org/10.1096/fj.14-251413

23. Junn E, Ronchetti RD, Quezado MM, Kim SY, Mouradian MM (2003) Tissue transglutaminase-induced aggregation of alphasynuclein: Implications for Lewy body formation in Parkinson's disease and dementia with Lewy bodies. Proc Natl Acad Sci USA 100:2047-2052. https://doi.org/10.1073/pnas.0438021100

24. Nurminskaya MV, Belkin AM (2012) Chapter one-cellular functions of tissue transglutaminase. Int Rev Cell Mol Biol 294:1-97. https://doi.org/10.1016/B978-0-12-394305-7.00001-X

25. Fesus L, Piacentini M (2002) Transglutaminase 2: an enigmatic enzyme with diverse functions. Trends Biochem Sci Oct 27(10):534-9. https://doi.org/10.1016/S0968-0004(02)02182-5

26. Joniec-Maciejak I, Ciesielska A, Wawer A, Sznejder-Pachołek A, Schwenkgrub J, Cudna A, Hadaczek P, Bankiewicz KS, Członkowska A, Członkowski A (2014) The influence of AAV2mediated gene transfer of human IL-10 on neurodegeneration and immune response in a murine model of Parkinson's disease. Pharmacol Rep 66:660-669. https://doi.org/10.1016/j.phare p.2014.03.008

27. Rowley HL, Martin KF, Marsden CA (1995) Determination of in vivo amino acid neurotransmitters by high-performance liquid chromatography with $o$-phthalaldehyde-sulphite derivatisation. J Neurosci Methods 57:93-99. https://doi.org/10.1016/01650270(94)00132-Z

28. Pfaffl MW (2001) A new mathematical model for relative quantification in real-time RT-PCR. Nucleic Acids Res 29:e45. https:// doi.org/10.1093/nar/29.9.e45

29. Vernier P, Moret F, Callier S, Snapyan M, Wersinger C, Sidhu A (2004) The degeneration of dopamine neurons in Parkinson's disease: insights from embryology and evolution of the mesostriatocortical system. Ann N Y Acad Sci 1035:231-249. https://doi. org/10.1196/annals.1332.015

30. Kanda T, Tsukagoshi H, Oda M, Miyamoto K, Tanabe H (1996) Changes of unmyelinated nerve fibers in sural nerve in amyotrophic lateral sclerosis, Parkinson's disease and multiple system atrophy. Acta Neuropathol 91:145-154. https://doi.org/10.1007/ s004010050406

31. Jubault T, Brambati SM, Degroot C, Kullmann B, Strafella AP, Lafontaine AL, Chouinard S, Monchi O (2009) Regional brain stem atrophy in idiopathic Parkinson's disease detected by anatomical MRI. PLoS ONE 4:e8247. https://doi.org/10.1371/journ al.pone.0008247

32. Kingsbury AE, Bandopadhyay R, Silveira-Moriyama L, Ayling H, Kallis C, Sterlacci W, Maeir H, Poewe W, Lees AJ (2010) Brain stem pathology in Parkinson's disease: an evaluation of the Braak staging model. Mov Disord 25:2508-2515. https://doi. org/10.1002/mds.23305

33. Braak H, Del Tredici K, Rüb U, de Vos RA, Jansen Steur EN, Braak E (2003) Staging of brain pathology related to sporadic Parkinson's disease. Neurobiol Aging 24:197-211. https://doi. org/10.1016/S0197-4580(02)00065-9

34. Schapira AH, Jenner P (2011) Etiology and pathogenesis of Parkinson's disease. Mov Disord 26:1049-1055. https://doi. org/10.1002/mds. 23732

35. Dehay B, Bourdenx M, Gorry P, Przedborski S, Vila M, Hunot S, Singleton A, Olanow CW, Merchant KM, Bezard E, Petsko GA, Meissner WG (2015) Targeting $\alpha$-synuclein for treatment of Parkinson's disease: mechanistic and therapeutic considerations. Lancet Neurol 14:855-866. https://doi.org/10.1016/S1474 $-4422(15) 00006-X$

36. Bendor JT, Logan TP, Edwards RH (2013) The function of $\alpha$-synuclein. Neuron 79:1044-1066. https://doi.org/10.1016/j. neuron.2013.09.004

37. Abeliovich A, Schmitz Y, Fariñas I, Choi-Lundberg D, Ho WH, Castillo PE, Shinsky N, Verdugo JM, Armanini M, Ryan A, Hynes M, Phillips H, Sulzer D, Rosenthal A (2000) Mice lacking alpha-synuclein display functional deficits in the nigrostriatal dopamine system. Neuron 25:239-252. https://doi.org/10.1016/ S0896-6273(00)80886-7 
38. Quintas A, Saraiva MJ, Brito RM (1999) The tetrameric protein transthyretin dissociates to a non-native monomer in solution. A novel model for amyloidogenesis. J Biol Chem 274:32943-32949. https://doi.org/10.1074/jbc.274.46.32943

39. Luth ES, Bartels T, Dettmer U, Kim NC, Selkoe DJ (2015) Purification of $\alpha$-synuclein from human brain reveals an instability of endogenous multimers as the protein approaches purity. Biochemistry 54:279-292. https://doi.org/10.1021/bi501188a

40. Kazantsev AG, Kolchinsky AM (2008) Central role of alphasynuclein oligomers in neurodegeneration in Parkinson disease. Arch Neurol 65:1577-1581. https://doi.org/10.1001/archn eur.65.12.1577

41. Jellinger KA (2004) Lewy body-related alpha-synucleinopathy in the aged human brain. J Neural Transm (Vienna) 111:1219-1235. https://doi.org/10.1007/s00702-004-0138-7

42. Dettmer U, Selkoe D, Bartels T (2016) New insights into cellular $\alpha$-synuclein homeostasis in health and disease. Curr Opin Neurobiol 36:15-22. https://doi.org/10.1016/j.conb.2015.07.007

43. Perez RG, Waymire JC, Lin E, Liu JJ, Guo F, Zigmond MJ (2002) A role for alpha-synuclein in the regulation of dopamine biosynthesis. J Neurosci 22:3090-3099. https://doi.org/10.1523/JNEUR OSCI.22-08-03090.2002

44. Braak H, Rüb U, Sandmann-Keil D, Gai WP, de Vos RA, Jansen Steur EN, Arai K, Braak E (2000) Parkinson's disease: affection of brain stem nuclei controlling premotor and motor neurons of the somatomotor system. Acta Neuropathol 99:489-495. https:// doi.org/10.1007/s004010051150

45. Yu S, Zuo X, Li Y, Zhang C, Zhou M, Zhang YA, Uéda K, Chan $P$ (2004) Inhibition of tyrosine hydroxylase expression in alphasynuclein-transfected dopaminergic neuronal cells. Neurosci Lett 367(1):34-39. https://doi.org/10.1016/j.neulet.2004.05.118

46. Stamnaes J, Fleckenstein B, Sollid LM (2008) The propensity for deamidation and transamidation of peptides by transglutaminase 2 is dependent on substrate affinity and reaction conditions. Biochim Biophys Acta 1784:1804-1811. https://doi.org/10.1016/j.bbapa p.2008.08.011

47. Lai TS, Liu Y, Tucker T, Daniel KR, Sane DC, Toone E, Burke JR, Strittmatter WJ, Greenberg CS (2008) Identification of chemical inhibitors to human tissue transglutaminase by screening existing drug libraries. Chem Biol 15:969-978. https://doi.org/10.1016/j. chembiol.2008.07.015

48. Ozansoy M, Başak AN (2013) The central theme of Parkinson's disease: $\alpha$-synuclein. Mol Neurobiol 47:460-465. https://doi. org/10.1007/s12035-012-8369-3
49. Jang GY, Jeon JH, Cho SY, Shin DM, Kim CW, Jeong EM, Bae HC, Kim TW, Lee SH, Choi Y, Lee DS, Park SC, Kim IG (2010) Transglutaminase 2 suppresses apoptosis by modulating caspase 3 and NF-kappaB activity in hypoxic tumor cells. Oncogene 29:356-367. https://doi.org/10.1038/onc.2009.342

50. Andringa G, Lam KY, Chegary M, Wang X, Chase TN, Bennett MC (2004) Tissue transglutaminase catalyzes the formation of alpha-synuclein crosslinks in Parkinson's disease. FASEB J 18:932-934. https://doi.org/10.1096/fj.03-0829fje

51. Luna E, Luk KC (2015) Bent out of shape: $\alpha$-Synuclein misfolding and the convergence of pathogenic pathways in Parkinson's disease. FEBS Lett 589:3749-3759. https://doi.org/10.1016/j.febsl et.2015.10.023

52. Lyytinen J, Kaakkola $S$, Ahtila $S$, Tuomainen $P$, Teräväinen $H$ (1997) Simultaneous MAO-B and COMT inhibition in L-Dopatreated patients with Parkinson's disease. Mov Disord 12:497505. https://doi.org/10.1002/mds.870120404

53. Goldstein DS, Sullivan P, Holmes C, Miller GW, Alter S, Strong R, Mash DC, Kopin IJ, Sharabi Y (2013) Determinants of buildup of the toxic dopamine metabolite DOPAL in Parkinson's disease. J Neurochem 126:591-603. https://doi.org/10.1111/jnc.12345

54. Masuda-Suzukake M, Nonaka T, Hosokawa M, Oikawa T, Arai T, Akiyama H, Mann DM, Hasegawa M (2013) Prion-like spreading of pathological $\alpha$-synuclein in brain. Brain 136:1128-1138. https ://doi.org/10.1093/brain/awt037

55. Politis M, Niccolini F (2015) Serotonin in Parkinson's disease. Behav Brain Res 277:136-145. https://doi.org/10.1016/j. bbr.2014.07.037

56. Tong Q, Xu Q, Xia Q, Yuan Y, Zhang L, Sun H, Shan H, Zhang K (2015) Correlations between plasma levels of amino acids and nonmotor symptoms in Parkinson's disease. J Neural Transm (Vienna) 122:411-417. https://doi.org/10.1007/s0070 2-014-1280-5

57. Cohen G, Farooqui R, Kesler N (1997) Parkinson disease: a new link between monoamine oxidase and mitochondrial electron flow. Proc Natl Acad Sci USA 94:4890-4894. https://doi.org/10.1073/ pnas.94.10.4890

Publisher's Note Springer Nature remains neutral with regard to jurisdictional claims in published maps and institutional affiliations. 